\title{
Иммиграционная политика \\ в праве Европейского союза
}

Юматова А.O.*

Миграция населения является своеобразным спутником научнотехнического прогресса и развития общества. Неудовлетворенность условиями жизни заставляет индивидов перемещаться в поисках лучшей жизни. Развитие и экономическое благосостояние одной страны подвержено влиянию и находится в зависимости от других стран (более развитых в экономическом и социальном отношении). Современная трудовая миграция этому подтверждение. Перед мировым сообществом вырисовывается глобальная проблема - проблема неконтролируемого переселения населения из бедных стран в богатые.

Огромная разница в уровне жизни и экономических возможностях в разных странах, растущая поляризация мира - основная движущая сила современной миграции. Кроме того, причинами миграции населения выступают серьезные экономические и политические кризисы, сопровождающиеся голодом, политическими репрессиями и межэтническими столкновениями.

Последние тенденции в иммиграционной политике различных стран свидетельствуют о том, что происходит постепенный переход от иммиграционного контроля к регулированию, т.е. управлению миграционными потоками, которое не может быть эффективным без межгосударственного сотрудничества. Для того чтобы воздействие миграции не было негативным, необходимо сотрудничество «отправляющих» и «принимающих» мигрантов стран. Именно такое взаимодействие и составляет основу политики миграционного регулирования. Регулирование иммиграции становится актуальным направлением и для Европейского союза, которому чрезвычайно важно реализовывать продуманную иммиграционную стратегию.

Следует отметить, что среди специалистов в области миграционных исследований довольно распространенной является точка зрения о том, что иммиграционная политика формируется не в отношении отдельно взятого государства или группы стран, а в отношении индивидов - выходцев из этих стран. При этом дифференцированное при-

\footnotetext{
* Юматова Анна Олеговна - аспирант кафедры международного права и европейского права Дипломатической академии МИД России.
} 
менение тех или иных мер к иммигрантам из различных государств объясняется вполне определенными экономическими, политическими и социальными причинами, а также особенностями историкокультурных связей между странами эмиграции и иммиграции. Тем не менее можно говорить о том, что не только межгосударственные отношения во всем их многообразии определяют в той или иной степени миграционную политику, но и сама миграционная политика оказывает воздействие на межгосударственные отношения.

Международное миграционное право представляет собой очень подвижный механизм, базирующийся на международно-правовых документах, региональных институтах и богатой национальной практике государств. Неотъемлемой частью осуществления международного миграционного права является предоставление убежища.

Убежище - специальный международно-правовой институт, который заключается в оказании покровительства лицу, вынужденному покинуть страну своего гражданства или пребывания. Основой права убежища является государственный суверенитет, поскольку в соответствии с рядом международных документов любому государству принадлежит исключительная прерогатива предоставления убежища на своей территории. Декларация о территориальном убежище 1967 года в п. 3 ст. 1 гласит: «Оценка оснований для предоставления убежища лежит на предоставляющем его государстве» ${ }^{1}$. Европейская Конвенция о территориальном убежище 1977 года в ст. 2 провозглашает право государств предоставлять убежище, в том числе и по обстоятельствам гуманитарного характера. Тем не менее государства отнюдь не стремятся ограничивать свой суверенитет универсальными международно-правовыми соглашениями, такими, например, как Конвенция о территориальном убежище. Идея создания единого документа была отвергнута в ходе работы над проектом Конвенции о территориальном убежище в 70-80-е годы прошлого столетия. Тогда государства не смогли найти единого подхода к реализации обязательств по предоставлению убежища. Декларации же, как известно, имеют лишь рекомендательный характер.

Опасения государств затронуть чужой суверенитет как нельзя лучше иллюстрирует ст. 1 Каракасской конвенции 1954 года о территориальном убежище, принятой Организацией американских государств:

1 Международные акты о правах человека: Сборник документов. М.: Издательская группа НОРМА-ИНФРА-М, 1998. С. 405. 
«Каждое государство имеет право в осуществление своего суверенитета допускать на свою территорию таких лиц, допуск которых оно сочтет целесообразным, так чтобы осуществление этого права не вызывало жалоб у какого-либо другого государства»².

Статус беженца в международном праве, осуществление фундаментальных прав и свобод человека в международном праве апеллируют к правам государства. Правом государства применительно к миграции выступает установление иммиграционных норм и правил, а правом индивида - механизм признания правового статуса иммигрантов и гарантий его реализации в стране пребывания. Важно отметить, что правовой статус беженца носит международно-правовой характер, причем отрицательное решение какого-либо государства о признании человека беженцем не освобождает другое государство, к которому он обращается, от рассмотрения просьбы о признании.

В Римском договоре об учреждении Европейского экономического сообщества 1957 года говорится о свободе передвижения лиц в пределах европейского сообщества, при этом имеется в виду только трудовая миграция. Что касается вынужденной миграции, то здесь регулирование остается в рамках универсальной Конвенции 1951 года и национального иммиграционного законодательства. Маастрихтский договор 1992 года о Европейском союзе установил единое гражданство Европейского союза и определил следующие сферы сотрудничества в области правосудия и внутренних дел: политика предоставления убежища, правила пересечения границ и иммиграционная политика. Затем последовали так называемые Шенгенские договоренности, которые состоят из Соглашения 1985 года «О постепенной отмене контроля на общих границах», Конвенции 1990 года «О применении Шенгенского соглашения от 14 июня 1985 года о постепенной отмене контроля на общих границах» (вступила в силу 25 марта 1995 года) и протоколов о присоединении. Договоренности оформлены отдельным протоколом к Амстердамскому договору 1997 года, который содержит раздел «Свободное передвижение лиц, право убежища и иммиграция». Принципиальным является положение Договора о признании государством-кандидатом всех пунктов договоренностей в качестве обязательного условия для рассмотрения вопроса о его присоединении к Европейскому союзу.

Что же является определяющим в иммиграционной политике Европейского союза?

2 Юридический справочник мигранта. М.: Классик Стиль, 2002. С. 125. 
С одной стороны, приоритет отдается максимальному упрощению перемещения граждан в пределах общих границ Европейского союза. С другой стороны, предусмотрено внедрение единых стандартов обращения с гражданами иных стран, въезжающих на территорию Европейского союза, создание жестких иммиграционных правил по отношению к беженцам и лицам, ищущим убежище, формирование общей процедуры признания их статуса. Третий аспект политики состоит в принятии общеевропейских мер по борьбе с незаконной миграцией и ее предотвращению.

Говоря о практике применения регионального регулирования миграции в рамках Европейского союза, нужно отметить, что единая Европа становится все более закрытой территорией для выходцев из стран - не членов Европейского союза. Этот принцип регулирования миграции вступает в противоречие с нормами Конвенции 1951 года о статусе беженцев. В качестве примеров ограничений по приему лиц, ищущих убежище в Европейском союзе, также можно привести:

- июнь 2003 года, когда Европейская Комиссия определила увеличение бюджета для приема иммигрантов и осуществления пограничного контроля на 2004-2006 годы на сумму в 140 миллионов евро. Средства должны были быть израсходованы на поддержку проектов по приграничному сотрудничеству, депортацию нелегальных иммигрантов и создание визовой информационной системы (VIS). Одновременно Комиссия поддержала предложение Великобритании по рассмотрению заявлений претендентов на убежище и статус беженца в непосредственной близости от зон конфликтов и организации такой процедуры с помощью региональных групп под эгидой Европейского союза и УВКБ ООН. Помимо этого Великобритания выдвинула идею перенести процедуру предоставления убежища за границы Европейского союза в специальные транзитные центры, которая Комиссией поддержана не была 3 ;

- октябрь 2003 года, когда на встрече министров внутренних дел в рамках единой европейской политики предоставления убежища было согласовано создание списка так называемых «безопасных стран», граждане которых не могут претендовать на убежище в странах Европейского союза. Министрами достигнуто также политическое согласие по поводу организации Европейской сети представителей иммиграционных служб в третьих странах 4 ;

3 Европейский союз: факты и комментарии. М.: «Интердиалект+», 2003. Вып. 33-34. ${ }^{4}$ Там же. 
- январь 2004 года, на встрече министров внутренних дел и юстиции стран Европейского союза в Дублине Комиссия ЕС заявила, что готова затратить 30

- миллионов евро на репатриацию (возвращение в государство гражданства, постоянного проживания или на историческую родину лиц, пребывавших по тем или иным причинам в других государствах $)^{5}$ нелегальных иммигрантов, а также финансировать пилотные проекты по приему и обустройству депортированных лиц в их государствах. Комиссия также выразила намерение до конца 2004 года заключить соглашения о реадмиссии с Марокко, Турцией, Россией и Украиной 6 . На указанной встрече верховный комиссар $\mathrm{OOH}$ по делам беженцев г-н Р. Лабберс обратил внимание министров на то, что число претендентов на убежище возрастает и их заявления придется рассматривать новым участникам Европейского союза, которые пока не готовы выдержать эту нагрузку самостоятельно. К предложенным мерам, и в частности к распределению финансового бремени по приему иммигрантов, министры отнеслись скептически ${ }^{7}$.

На взгляд автора статьи, приведенные факты свидетельствуют о наметившейся в современной иммиграционной практике тенденции игнорирования базовых норм Конвенции 1951 года о статусе беженцев. Ограничение контингента потенциальных беженцев, стремление к соглашениям о реадмиссии лиц, ищущих убежище на территории транзитных для них стран - все это свидетельствует о примате региональных механизмов и узкоевропейских интересов по отношению к универсальным международно-правовым стандартам прав человека. Наглядным правовым подтверждением политики «закрытых дверей» служит ст. 29 Конвенции 1990 года о применении Шенгенского соглашения, где ч. 1 и ч. 2 вступают в явное противоречие друг с другом:

«1. Договаривающиеся стороны обязуются рассматривать любое ходатайство о предоставлении убежища, поданное иностранцем на территории любой из них.

2. Это обязательство не требует, чтобы Договаривающаяся сторона разрешалакаждомузаявителювъезжатьилиоставатьсянаеетерритории.

5 Юридический энциклопедический словарь / Под ред. М.Н. Марченко. ТК «Велби», издательство «Проспект», 2006.

${ }^{6}$ Как известно, с Россией указанное Соглашение подписано и вступило в силу с 1 июня 2007 г.

7 Там же. 
Каждая Договаривающаяся сторона сохраняет за собой право отказать во въезде заявителю, ходатайствующему о предоставлении убежища, или выслать его в третье государство на основании своих национальных законов и в соответствии со своими международными обязательствами» ${ }^{8}$.

Тем не менее следует отметить, что на протяжении многих лет государства - члены Европейского союза пытаются адекватно реагировать на иммиграцию, которая представляется довольно парадоксальным феноменом. С одной стороны, миграция может способствовать решению демографических и экономических проблем, а с другой может провоцировать социальную нестабильность и рассматриваться как угроза внутренней безопасности стран Союза. Учитывая же углубление и расширение интеграционных процессов в Европе, можно сделать вывод, что решение иммиграционных проблем в рамках одного государства невозможно. В последние годы проблемы, порождаемые иммиграцией, в европейских странах достигли критической стадии.

Статистика говорит об устойчивом росте нелегальной иммиграции и распространении в европейском обществе ксенофобии. Так термин «нелегальная миграция» используется для описания целого ряда явлений. Под него подпадают и граждане третьих стран, которые нелегально въезжают на территорию государства-члена по суше, по воде или по воздуху, включая транзитные зоны в аэропортах. Часто это делается с использованием фальшивых или поддельных документов либо с помощью организованных преступных сетей контрабандистов или торговцев людьми. Помимо этого значительное количество людей легально въезжают в страну по действительной визе или по безвизовому режиму, но находятся в стране свыше разрешенного срока или меняют цель приезда без разрешения властей. Наконец, есть несостоявшиеся лица, ищущие убежища, которые не покидают страну после вынесения окончательного отрицательного решения по их ходатайству.

Примерные оценки потоков нелегальной миграции могут быть получены только из имеющих к ним отношение показателей, таких как количество отказов во въезде, число нелегальных иммигрантов, за-

8 Шенгенские соглашения: Соглашение между Правительствами государств Экономического союза Бенилюкс, ФРГ и Французской Республики о постепенной отмене проверок на общих границах; Конвенция о применении Шенгенского соглашения от 14 июня 1985 года между Правительствами государств Экономического союза Бенилюкс, ФРГ и Французской Республики о постепенной отмене проверок на общих границах. М.: «Профобразование», 2000. 
держиваемых на границе или на территории государства-члена, число ходатайств о национальных процедурах регуляризации и число выдворений. Еще одним полезным индикатором служит значительное количество лиц, которые легально въезжают в страну, а затем «просрочивают» свое пребывание. Судя по этим показателям, примерный объем ежегодных потоков нелегальной иммиграции в Европейском союзе выражается в шестизначных числах.

Нелегальные миграционные перемещения больших количеств людей, вероятно, будут продолжаться до тех пор, пока будут сохранять свою значимость «выталкивающие» факторы в третьих странах и «притягивающие» факторы в Европейском союзе.

Проблемы безработицы в массовом сознании уже давно связаны с волнами приезжающих на временное и постоянное место жительства. Современные миграционные тенденции делают вопрос о проведении эффективной иммиграционной политики одним из наиболее актуальных в повестке дня практически всех государств - членов Европейского союза.

Амстердамский договор, вступивший в силу в 1999 году, стал решающим шагом на пути полной коммунитаризации иммиграционной политики. Ряд положений Договора призван способствовать формированию общей иммиграционной политики Европейского союза, направленной на создание «пространства свободы, безопасности и правосудия». Тем не менее некоторые исследователи считают, что общая иммиграционная политика Европейского союза - факт далеко не однозначный. Однако можно утверждать, что процесс формирования такой политики - объективная реальность, а некоторые ее элементы вполне очевидны.

Например, в настоящее время наблюдается постепенное приближение национальных иммиграционных политик к некой средней общеевропейской модели. В сентябре 2000 года был создан Европейский фонд помощи беженцам. Европейская Комиссия разработала ряд программ с целью интеграции легальных иммигрантов в общество, основанных прежде всего на облегчении их доступа на рынок труда.

Совет ЕС принял директивы, касающиеся воссоединения семей и статуса граждан третьих стран, долгое время проживающих на территории государств-членов. Кроме того, в целях борьбы с нелегальной иммиграцией летом 2003 года в Европейском союзе была создана специальная рабочая группа. Правда, вошли в нее всего лишь пять 
государств-членов: Германия, Испания, Италия, Франция, всегда поддерживающие формирование общей иммиграционной политики Европейского союза, а также Великобритания, стремящаяся отстоять особую позицию. Все эти события свидетельствуют об активной деятельности Европейского союза по формированию общей иммиграционной политики.

На саммитах Европейского совета с 1998 года (в Вене) до 2007 года (в Брюсселе) были обозначены основные направления формирования коммунитарной иммиграционной политики:

- развитие партнерства со странами происхождения иммигрантов (возможность включения этой проблематики в Общую Внешнюю Политику и Политику Безопасности);

- создание общей европейской системы предоставления убежища 9 ;

9 К моменту очередной волны расширения Европейского союза с 15 до 25 членов, а затем до 27 в коммунитарном законодательстве содержались достаточно разработанные нормы, ориентирующие в отношении возможных действий институтов ЕС по вопросам беженцев. Это дало возможность при разработке Гаагской программы по созданию пространства свободы, безопасности и правосудия включить в текст документа тезис о целесообразности создания Общей европейской системы по предоставлению убежища к 2010 г. Первый этап в реализации этой цели предусматривал необходимость разработки нормативных актов, которые бы решали задачу гармонизации национальных законодательств государств - членов ЕС по вопросам предоставления убежища. Следует отметить, что к этому времени в рамках Европейского сообщества уже были предприняты первые попытки координации действий государств. Так, были приняты директива Совета 2001/55/ЕС от 20 июля 2001 г. «О минимальных стандартах предоставления временной защиты в случае массового притока перемещенных лиц и о мерах поддержания баланса в усилиях государств-членов в связи с приемом таких лиц и последствиями такого приема», а также так называемый Дублинский регламент 343/2003 от 18 февраля 2003 г. «О критериях и механизмах для определения государства-члена, ответственного за рассмотрение ходатайства о предоставлении убежища, поданного в одном из государств-членов гражданином третьей страны». Однако их было явно недостаточно для того, чтобы обеспечить принятие согласованных мер государствами-членами в случае массового притока беженцев. Первая фаза создания Общей европейской системы по предоставлению убежища предполагала гармонизацию не только законодательства, но и практики его применения, что, в свою очередь, было призвано повысить качество принимаемых решений в контексте согласованных процедур и привести к повышению доверия между государствами-членами и обеспечить последовательность практических шагов в рамках Европейского союза. С этой целью в соответствии с задачами по созданию Общей европейской системы по предоставлению убежища институты ЕС разработали и приняли три ключевых документа: директиву Совета 2003/9/ЕС от 27 января 2003 г., определяющую минимальные стандарты приема лиц, ищущих убежища; директиву Совета 2004/83/ЕС от 29 апреля 2004 г. 
- справедливое обращение с гражданами третьих стран ${ }^{10}$;

- управление миграционными потоками ${ }^{11}$.

Проявлением перехода Европейского союза от мер контроля к регулированию иммиграции является включение некоторых мер иммиграционной политики в отношения Европейского союза с третьими странами. При реализации такой стратегии принимающими государствами страны происхождения иммигрантов оказываются вовлеченными в поле действия иммиграционной политики. В этом случае иммиграционная политика в отношении индивидов осуществляется в рамках миграционного режима, установленного между государствами.

о минимальных стандартах для квалификации и статуса граждан третьих стран или лиц без гражданства в качестве беженцев или лиц, нуждающихся в иной форме международной защиты, и содержании предоставляемой защиты; директиву Совета 2005/85/ ЕС от 1 декабря 2005 г. о минимальных стандартах для процедур государств-членов по предоставлению и отмене статуса беженца.

В результате принятия вышеуказанных директив была успешно завершена первая фаза создания Общей европейской системы по предоставлению убежища. По мнению Комиссии ЕС, на втором этапе этого процесса предполагается разработать общую процедуру предоставления убежища, а также унифицировать нормы, регламентирующие статус лиц, которым предоставлены убежище или дополнительная защита. Кроме того, на базе национальных служб, занимающихся вопросами убежища, необходимо создать такую структуру, которая содействовала бы практическому взаимодействию государств-членов с целью утверждения единой процедуры ЕС по предоставлению убежища.

10 Долгое время важнейшие компоненты «свободного передвижения лиц» на территории единого рынка Европейского союза, в том числе «свобода передвижения работников», оставались закрытыми для граждан государств, не входивших в состав Европейского союза. В целом, трудящиеся и другие мигранты из «третьих стран», даже получив вид на жительство в одном из государст-членов, не были правомочны в отличие от граждан Союза - свободно переселяться в другие государства-члены и заниматься там трудовой или предпринимательской деятельностью. Частичное преодоление указанной дискриминации становится возможным благодаря законодательным актам Европейского союза, утвержденным Советом Европейского союза в конце 2003 года. (Директива 2003/109/ЕС «О статусе граждан третьих стран, проживающих на долгосрочной основе» - закрепляет основы правового положения легальных иммигрантов из зарубежных стран, включая принцип их равноправия с гражданами Европейского союза. Директива 2003/86/EC «О праве на семейное воссоединение»закрепляет основы для переезда в Союз членов семей легальных иммигрантов, а также предоставляет им возможность заниматься в государствах-членах трудовой или иной социально-экономической деятельностью).

11 В этой сфере приоритетное внимание уделяется проверкам на границах и борьбе с нелегальной миграцией, биометрической и информационной системам и визовой политике. 
Миграционная политика внутри самого Европейского союза выстраивается в прямой зависимости от характера юридической связи индивида и государства. Только граждане государств - членов Европейского союза в полном объеме пользуются правом на свободное передвижение в рамках Союза со всеми сопутствующими привилегиями. От этого внутреннего миграционного регулирования следует отличать политику в отношении граждан новых членов Европейского союза, которая носит компромиссный характер, и иммиграционную политику в отношении граждан государств, не входящих в Европейский Союз - “immigration policy towards third country nationals" или "common immigration policy".

Большинство первоначальных государств - членов Европейского союза заявили, что они ограничат свободный доступ на их территорию граждан новых стран - участниц Европейского союза на время переходного периода ${ }^{12}$. Фактически речь идет о том, что данной категории населения Европейского союза отказано в праве свободного трудоустройства в государствах Западной Европы, причем ограничения эти варьируются по срокам и по другим параметрам от страны к стране. Такие меры государств-членов вызывают критику со стороны Еврокомиссии. Наряду с этим признается вероятность более масштабного использования территории новых государств - членов Европейского союза для транзита нелегальных иммигрантов из других регионов. В итоге новым государствам-членам приходится просто смириться с тем фактом, что одним из условий их вступления в Европейский союз было обязательство принятия жестких правил его миграционного режима.

Похожая ситуация складывается и при формировании иммиграционной политики Европейского союза. Решение об интеграции иммиграционной политики во внешнюю политику Союза было принято на саммите в Лакене в 2001 году.

Миграционная теория и практика предполагает два варианта того, как может реализовываться миграционная стратегия. Первый вариант подразумевает применение мер карательного характера по отношению к государствам, которые не стремятся сдерживать массовые волны эмигрантов. По большей части это экономические санкции,

12 Например, Нидерланды установили переходный период всего в один год, а вот Дания, Германия, Франция, Италия и Австрия избрали семилетний период-предельно допустимый по законам ЕС срок для испытательной адаптации «новых европейцев». 
а также ужесточение иммиграционного контроля именно в отношении выходцев из этих стран. Эта стратегия может быть условно обозначена как «негативное» воздействие на страны эмиграции, эффект которого носит краткосрочный характер, так как не происходит устранения причин эмиграции.

Альтернативой такому решению служит широко известный за рубежом «причинный подход» (root causes approach), когда применяются превентивные меры, направленные на устранение причин массовой эмиграции из того или иного государства. На практике это выражается в финансовой и технической помощи развитию для решения прежде всего экономических проблем. Этот подход представляет собой «позитивное» воздействие на страны, подверженные эмиграции, при этом высока вероятность достижения желаемого эффекта.

Таким образом, Европейский союз фактически пытается увязать оба подхода. Однако следует констатировать, что странам Европейского союза так и не удалось принять решение о безоговорочно жесткой позиции в отношении тех стран, которые не желают должным образом сотрудничать с Европейским союзом в целях предотвращения нелегальной иммиграции. В связи с имеющимися разногласиями о мерах воздействия на данном этапе Европейский союз стремится к заключению соглашений о реадмиссии со странами эмиграции ${ }^{13}$. Совет министров ЕС охарактеризовал их как «чрезвычайно полезный и эффективный инструмент в борьбе с нелегальной иммиграцией». Основная цель таких соглашений состоит в том, чтобы наладить механизм почти автоматического возвращения нелегалов в страну их проживания.

Соглашения о реадмиссии, по оценкам специалистов, действительно являются жестким инструментом борьбы с нелегальной иммиграцией. Наравне с обязательствами относительно собственных граждан государство, которое подписывает с Европейским союзом соглашение по реадмиссии, берет на себя обязательства по приему лиц без гражданства или тех, кто имеет иную юрисдикцию, если они нелегально въехали в Европейский союз с территории страны, с которой заключено соглашение. А сами соглашения о реадмиссии повышают

13 Понятие «реадмиссия» означает возвращение въехавших в Шенгенское пространство иммигрантов и лиц, ищущих убежище, тому государству (обычно приграничному), с территории которого они прибыли. Данная процедура осуществляется на основе двусторонних соглашений. 
ответственность страны, как за ее граждан, так и за лиц с иным юридическим статусом, находящихся на ее территории. Таким образом, в реализации своей иммиграционной стратегии Европейский союз стремится к воздействию не только на иммигрантов, но и на страны их происхождения.

Страны Европейского союза стали рассматривать находящихся на их территории легальных и нелегальных иммигрантов как объективную реальность. Это обстоятельство может оказаться решающим в проведении сбалансированной, взвешенной политики. Однако пока отдельные страны Европейского союза имеют достаточное пространство для маневра в данной области, перекосы неизбежны. Стремление ряда государств получать выгоды от притока дешевой рабочей силы, не разделяя при этом иммиграционного бремени, сдерживает эффективность миграционной стратегии Европейского союза. Поэтому лишь полная коммунитаризация иммиграционной политики может способствовать достижению принципиальных целей: решению проблемы старения населения, гарантированию занятости в ряде секторов экономики при условии безопасности и социальной стабильности в государствах Союза. 


\section{The Immigration Policy in the Law \\ of the European Union \\ (Summary)}

\section{Anna O. Yumatova*}

The development of the international economy is closely related to the immigration process. The European Union is an significant member of the world policy, thus studying the immigration in the frame of the European Union is very important. The article "The immigration policy in the law of the European Union" is devoted to the analysis of the law development of the immigration process in the European Union. The attention is paid to the law progress and the main stages of its development. The author of the article bases her research on the international law sources showing the continuity in solutions of the immigration issues in the European area. Attention is paid to the spread of immigration and motives of its origination. Studying the immigration policy the author comes to the conclusion that not all the European Union states pay sufficient attention to this question and tend to use cheap work-force in their economies. In the author's opinion it is necessary to cooperate for the stability and solving main problems in the immigration policy sphere of the European Community.

\footnotetext{
* Anna O. Yumatova - post-graduate student of the Chair of International and European law, Diplomatic Academy MFA Russia.
} 